\title{
High piezoelectricity after field cooling AC poling in temperature stable ternary single crystals manufactured by continuous-feeding Bridgman method
}

\author{
Cong LUO ${ }^{a, b}$, Tomoaki KARAKI ${ }^{b, *}$, Zhuangkai $\mathrm{WANG}^{b}$, Yiqin $\mathrm{SUN}^{b}$, \\ Yohachi (John) YAMASHITA ${ }^{b, c}$, Jiayue XU ${ }^{a,{ }^{*}}$ \\ ${ }^{a}$ School of Materials Science and Engineering, Shanghai Institute of Technology, \\ Shanghai 201418, China \\ ${ }^{b}$ Department of Electrical and Computer Engineering, Faculty of Engineering, \\ Toyama Prefectural University, Toyama 939-0398, Japan \\ ${ }^{c}$ Department of Mechanical \& Aerospace Engineering, North Carolina State University, \\ NC 27695-7910, USA
}

Received: March 15, 2021; Revised: July 28, 2021; Accepted: July 31, 2021

(C) The Author(s) 2021.

\begin{abstract}
After field cooling (FC) alternating current poling (ACP), we investigated the dielectric and piezoelectric properties of [001 $]_{\mathrm{pc}}$-oriented $0.24 \mathrm{~Pb}\left(\mathrm{In}_{1 / 2} \mathrm{Nb}_{1 / 2}\right) \mathrm{O}_{3}(\mathrm{PIN})-0.46 \mathrm{~Pb}\left(\mathrm{Mg}_{1 / 3} \mathrm{Nb}_{2 / 3}\right) \mathrm{O}_{3}(\mathrm{PMN})-$ $0.30 \mathrm{PbTiO}_{3}(\mathrm{PT})(\mathrm{PIMN}-0.30 \mathrm{PT})$ single crystals (SCs), which were manufactured by continuousfeeding Bridgman (CF BM) within morphotropic phase boundary (MPB) region. By ACP with $4 \mathrm{kV}_{\text {rms }} / \mathrm{cm}$ from 100 to $70{ }^{\circ} \mathrm{C}$, the PIMN-0.30PT SC attained high dielectric permittivity $\left(\varepsilon_{33}^{T} / \varepsilon_{0}\right)$ of 8330 , piezoelectric coefficient $\left(d_{33}\right)$ of $2750 \mathrm{pC} / \mathrm{N}$, bar mode electromechanical coupling factor $k_{33}$ of 0.96 with higher phase change temperature $\left(T_{\mathrm{pc}}\right)$ of $103{ }^{\circ} \mathrm{C}$, and high Curie temperature $\left(T_{\mathrm{C}}\right)$ of $180{ }^{\circ} \mathrm{C}$. These values are the highest ever reported as PIMN- $x$ PT SC system with $T_{\mathrm{pc}}>100{ }^{\circ} \mathrm{C}$. The enhancement of these properties is attributed to the induced low symmetry multi-phase supported by phase analysis. This work indicates that FC ACP is a smart and promising method to enhance piezoelectric properties of relaxor-PT ferroelectric SCs including PIMN- $x \mathrm{PT}$, and provides a route to a wide range of piezoelectric device applications.
\end{abstract}

Keywords: field cooling (FC) alternating current poling (ACP); PIMN-0.30PT; high piezoelectricity

\section{Introduction}

Lead magnesium niobate $\mathrm{Pb}\left(\mathrm{Mg}_{1 / 3} \mathrm{Nb}_{23}\right) \mathrm{O}_{3}(\mathrm{PMN})-$

\footnotetext{
* Corresponding authors.

E-mail: T. Karaki, chen@pu-toyama.ac.jp;

J.Xu,xujiayue@sit.edu.cn
}

lead titanate $\mathrm{PbTiO}_{3}(\mathrm{PT})$ based relaxor ferroelectric single crystals (SCs) have attracted extensive attention over the last 20 years, compared to the conventional polycrystalline lead zirconate titanate (PZT) ceramics [1-3]. Owing to their high piezoelectric properties as the key component of electromechanical devices, including medical imaging, actuators, underwater acoustic ultrasound, and nondestructive testing evaluation 
transducer, their excellent performance and applications have also promoted the rapid development of various growth methods of SCs. As a conventional relaxor-PT $\mathrm{SC}$ growth process, one charge Bridgman (OC BM) causes nonuniformity of $\mathrm{TiO}_{2}$ concentration along growth direction due to the compositional segregation. Consequently, it leads to a large variation of dielectric and piezoelectric properties within a whole SC ingot [1]. In order to eliminate the compositional segregation, a continuous-feeding Bridgman (CF BM) method has developed in 2011 by Matsushita and Echizenya [4,5] of JFE Mineral Co., Ltd., Japan, which has been commercialized in the last decade. Until now, they have successfully grown high homogeneous binary PMN-0.30PT and ternary $\mathrm{Pb}\left(\operatorname{In}_{12} \mathrm{Nb}_{12}\right) \mathrm{O}_{3}$ (PIN)-PMN$x$ PT SCs with large size of more than $80 \mathrm{~mm}$ in diameter and $300 \mathrm{~mm}$ in length by the CF BM method [5].

There is no doubt that electric poling is an essential process to obtain proper piezoelectric properties of relaxor-PT SCs. Electric field cooling (FC) direct current poling (DCP) for $\mathrm{Pb}\left(\mathrm{Zn}_{1 / 3} \mathrm{Nb}_{23}\right) \mathrm{O}_{3}(\mathrm{PZN})-\mathrm{PT}$ and PMN-PT SCs, by applying about $10 \mathrm{kV} / \mathrm{cm}$ from $200{ }^{\circ} \mathrm{C}$ (above Curie temperature $\left(T_{\mathrm{C}}\right)$ in cubic $(\mathrm{C})$ phase) to room temperature (RT), has been studied to enhance the piezoelectric properties since 1982. These binary SCs, such as PZN-PT and PMN-PT, have relatively low Curie temperature $\left(T_{\mathrm{C}}=120-170{ }^{\circ} \mathrm{C}\right)$ and low coercive field $\left(E_{\mathrm{c}}=2-3.5 \mathrm{kV} / \mathrm{cm}\right)$. However, these behaviors limit applications in transducers indeed, and utilization scope would be further restricted by ferroelectric phase change temperature $\left(T_{\mathrm{pc}}\right)$ of $T_{\mathrm{RM}} / T_{\mathrm{MT}}$ (R: rhombohedral; $\mathrm{M}$ : monoclinic; $\mathrm{T}$ : tetragonal), which occurs at a significantly lower level $\left(T_{\mathrm{pc}}=50-100{ }^{\circ} \mathrm{C}\right)$ than $T_{\mathrm{C}}$. Thus, SC systems with high $T_{\mathrm{pc}}$ and $T_{\mathrm{C}}$ for enhanced temperature usage range are desired to meet the thermal stability requirement which could avoid the influence of thermal generated by high-power electromechanical devices, such as sonar transducers. In order to obtain high electrical properties with high $T_{\mathrm{pc}}, T_{\mathrm{C}}$, and $E_{\mathrm{c}}$, ternary SCs PIMN $-x$ PT are regarded as the best composition [6].

In 2014, Yamamoto et al. [7,8] reported that dynamic alternating current poling (ACP) is an effective process to further enhance electrical properties of PMN-PT and PIMN-PT SCs compared with traditional static DCP process. Since then, many ACP studies, involving compositions, domain structure, orientations, transparency, and electric filed condition for relaxor-PT SCs, have been conducted in last several years [9-34]. Among them, the effect of ACP temperature dependence of $\mathrm{PMN}-x \mathrm{PT}$ SC properties was investigated by some groups $[13,26]$. The close relationship between the optimal ACP temperature and performance was also revealed. Meanwhile, present authors reported high temperature $\mathrm{ACP}$ at $90{ }^{\circ} \mathrm{C}$ for 0.24PIN-0.46PMN-0.30PT (PIMN-0.30PT) CF BM $\mathrm{SC}$ and obtained $\varepsilon_{33}^{T} / \varepsilon_{0}=7000, d_{33}=2340 \mathrm{pC} / \mathrm{N}$, and bar mode electromechanical coupling factor $k_{33}=$ 0.95 [29]. Besides, Ma et al. [19] reported combination poling of DCP and ACP for $0.25 \mathrm{PIN}-0.43 \mathrm{PMN}-$ $0.32 \mathrm{PT}$ OC BM SC and obtained $\varepsilon_{33}^{T} / \varepsilon_{0}=7210$, $d_{33}=2610 \mathrm{pC} / \mathrm{N}$, with $T_{\mathrm{pc}}=114{ }^{\circ} \mathrm{C}$.

However, there is no report showing $\varepsilon_{33}^{T} / \varepsilon_{0}>8000$, $d_{33}>2700 \mathrm{pC} / \mathrm{N}$, and $k_{33}>0.95$ with above $100{ }^{\circ} \mathrm{C} T_{\mathrm{pc}}$ of ternary SCs. The FC ACP for PMN-0.30PT and PIMN-0.26PT SCs was firstly investigated in our previous work, and also proved as an effective process for improving the electric performance and thermal stability of PMN-based SCs [25]. Taking into account the interaction among different factors in the ACP process due to dynamic phase transition during cooling, it is particularly important to achieve enhanced electric and thermal performance through optimizing the cooling zone and electric field conditions. Therefore, in this paper, we investigated effect of FC ACP process on CF BM PIMN-0.30PT SCs to improve electrical properties with higher $T_{\mathrm{pc}}$.

\section{Experiments}

The PIMN-0.30PT SCs (JFE Mineral Co., Ltd., Chiba, Japan) grown along $[011]_{\mathrm{pc}}$ direction manufactured by the CF BM method were used in this research. Pseudocubic perovskite indication was used in our work. These SC samples with a rectangular plate of $(W) 5.0 \mathrm{~mm} \times(L) 5.0 \mathrm{~mm} \times(T) 0.4 \mathrm{~mm}$ were prepared along [001] $]_{\mathrm{pc}}$ with $300 \mathrm{~nm}$ gold (Au) electrodes as shown in Fig. 1(a). Dynamic phase transition with decreasing temperature in FC ACP process is illustrated with diagram in Fig. 1(c). The FC poling process performed in air atmosphere without silicone oil [25], has an advantage of a free of organic solvent after poling of SC plates. In order to compare the ACP voltage and DCP voltage, we applied a root mean square (RMS) voltage per centimeter $\left(\mathrm{V}_{\mathrm{rms}} / \mathrm{cm}\right)$ as all electric field condition units. The term "rms" also called the effective or heating value of alternating current 


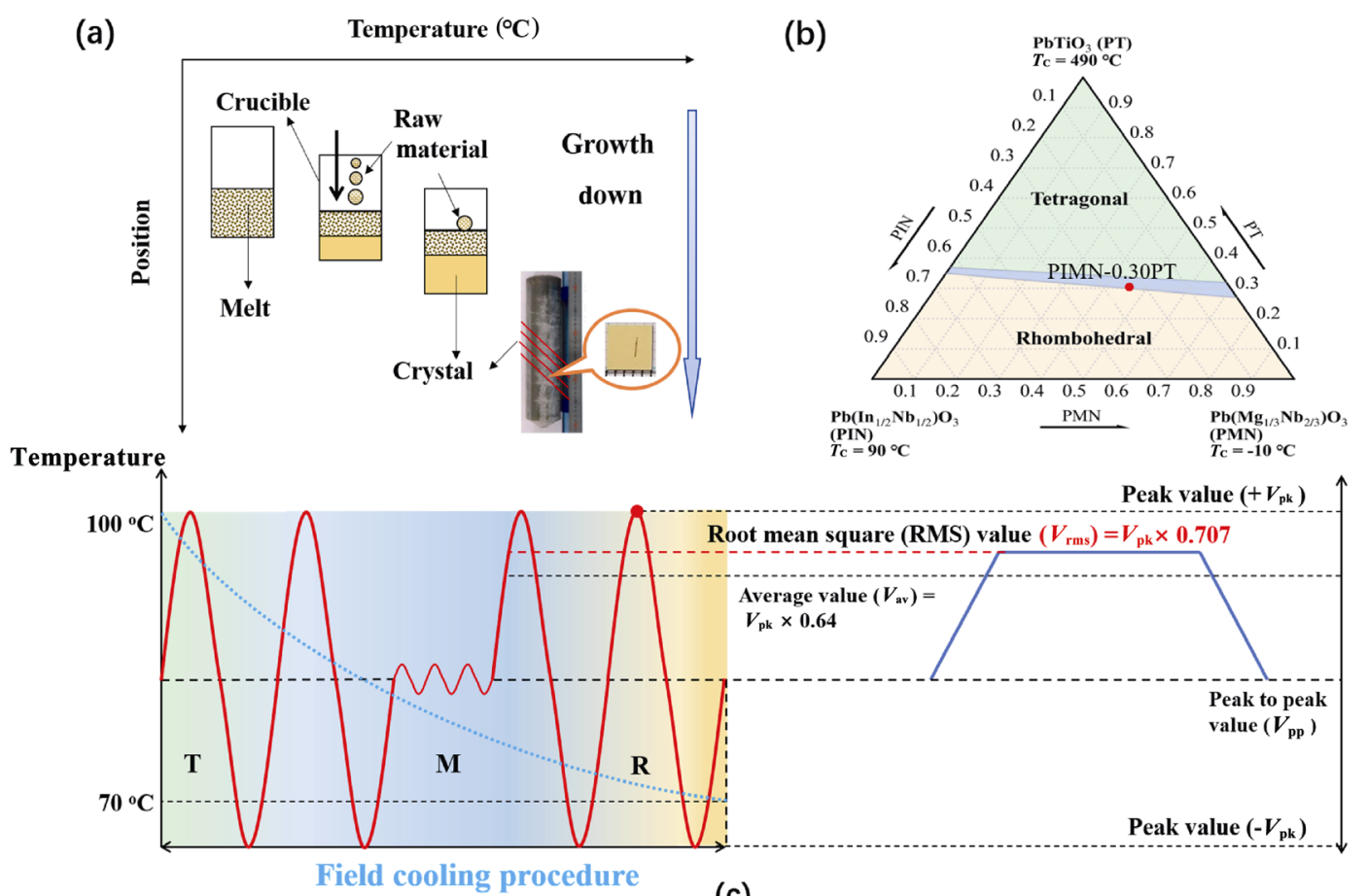

(c)

Fig. 1 PIMN-0.30PT SCs manufactured by (a) CF BM method, possessing multi-phase structure located in morphotropic phase boundary (MPB) region nearby R phase, are illustrated in (b) ternary phase diagram [15]. The entire FC ACP system of the PIMN-0.30PT SCs, through (c) phase transition path of $\mathrm{T} \rightarrow \mathrm{M} \rightarrow \mathrm{R}$ during cooling, was performed in air atmosphere.

(AC), is equivalent to the direct current (DC) voltage and energy that would provide the same amount of heat generation in a resistor. The AC Vrms was calculated by multiplying $71 \%$ of the $\mathrm{AC}$ sine wave peak voltage $\left(V_{\mathrm{pk}}\right)$. All samples were kept for $10 \mathrm{~min}$ at RT after poling, and started the measurement of capacitance and loss by impedance analyzer (Agilent Technology, 4194 A, CA, USA) at 19-29 ${ }^{\circ} \mathrm{C}$. Meanwhile, the temperature dependence coefficients (TDC) were also calculated. The free dielectric permittivity $\left(\varepsilon_{33}^{T} / \varepsilon_{0}\right)$ and clamped dielectric permittivity $\left(\varepsilon_{33}^{S} / \varepsilon_{0}\right)$ were calculated from the measured capacitance with a frequency at $1 \mathrm{kHz}$ and at the two times of anti-resonant frequency $\left(2 f_{\mathrm{a}}\right)$. Bar mode electromechanical coupling factor $k_{33}$ was obtained from $\varepsilon_{33}^{T} / \varepsilon_{0}$ and $\varepsilon_{33}^{S} / \varepsilon_{0}$ according to Eq. (1) $[6,15]$ :

$$
k_{33}=\sqrt{\frac{\varepsilon_{33}^{T} / \varepsilon_{0}-\varepsilon_{33}^{S} / \varepsilon_{0}}{\varepsilon_{33}^{T} / \varepsilon_{0}}}
$$

The electromechanical coupling factor $\left(k_{t}\right)$ of SC plate was calculated according to IEEE standards [35,36]. The $d_{33}$ was measured at RT using piezo $d_{33} / d_{31}$ meter (Institute of Automation, Chinese Academy of Sciences, ZJ-6B, China). Furthermore, temperature dependence of $\varepsilon_{33}^{T} / \varepsilon_{0}$ and dielectric loss $(\tan \delta)$ for SCs were obtained by a computer-controlled LCR meter (Hioki E. E. Co., IM-3570, Nagano, Japan) at $1 \mathrm{kHz}$ from $\mathrm{RT}$ to $250{ }^{\circ} \mathrm{C}$.

\section{Results and discussion}

These material constants (MCs) of $\varepsilon_{33}^{T} / \varepsilon_{0}, \varepsilon_{33}^{S} / \varepsilon_{0}$, and $d_{33}$ for PIMN-PT SCs have large TDC, as reported by Qiao et al. [37]. To compare the poling process effects of all MCs exactly, we applied $\mathrm{MC}_{25}$ at $25.0{ }^{\circ} \mathrm{C}$ calculated in Eq. (2) according to Electronic Industries Alliance (EIA) RS 128 standard:

$$
\mathrm{MC}_{25}=\frac{\mathrm{MC}_{T}}{1+\mathrm{TDC} \times(T-25.0)}
$$

where $\mathrm{MC}_{25}$ is the material constant at $25.0{ }^{\circ} \mathrm{C}, \mathrm{MC}_{T}$ is material constant at real measured temperature, and $T$ is measured temperature. The actual measured TDC values of $\varepsilon_{33}^{T} / \varepsilon_{0}, d_{33}$, and $\varepsilon_{33}^{S} / \varepsilon_{0}$ of the PIMN$0.30 \mathrm{PT}$ SC were 8500,8800 , and $6700 \mathrm{ppm} /{ }^{\circ} \mathrm{C}$, respectively.

Table 1 shows the dielectric and piezoelectric properties of the PIMN-0.30PT SCs poled by diverse temperature and electric field conditions. To facilitate comparison, all calculated $\mathrm{MC}_{25}$ are shown in Table 1. 
Table 1 Poling conditions and electrical properties of PIMN-0.30PT SCs

\begin{tabular}{cccccccccccc}
\hline No. & Poling & Voltage $^{a}$ Frequency $(\mathrm{Hz})$ & Cycle & Temperature $\left({ }^{\circ} \mathrm{C}\right)$ & $\varepsilon_{33}^{T} / \varepsilon_{0}$ & $\varepsilon_{33}^{S} / \varepsilon_{0}$ & Loss $(\%)$ & $k_{\mathrm{t}}(\%)$ & $k_{33}(\%)$ & $d_{33}(\mathrm{pC} / \mathrm{N})$ \\
\hline 1 & HT DCP & 8 & - & - & 50 & 5110 & 600 & 0.39 & 59.0 & 95.8 & 1760 \\
$2^{b}$ & HT ACP & 4 & 10 & 12 & 90 & 7000 & 680 & 0.59 & 59.3 & 95.0 & 2340 \\
3 & FC ACP & 4 & 0.06 & 20 & $120-60$ & 7270 & 680 & 0.77 & 55.2 & 95.2 & 2370 \\
4 & FC ACP & 4 & 0.2 & 20 & $100-80$ & 6720 & 650 & 0.86 & 57.7 & 95.0 & 2310 \\
5 & FC ACP & 6 & 0.1 & 20 & $100-70$ & 7940 & 660 & 0.54 & 55.9 & 95.8 & 2200 \\
6 & FC ACP & 6 & 0.1 & 20 & $100-60$ & 8040 & 800 & 0.89 & 58.3 & 94.9 & 2600 \\
7 & FC ACP & 4 & 0.1 & 20 & $100-70$ & 8330 & 660 & 0.33 & 58.2 & 96.0 & 2750 \\
\hline
\end{tabular}

${ }^{a} \mathrm{All}$ voltage units are $\mathrm{kV}_{\mathrm{rms}} / \mathrm{cm}$.

${ }^{b}$ No. 2 is the result of previous published work [29].

No. 3 with lower frequency $(0.06 \mathrm{~Hz})$ applied $4 \mathrm{kVrms} / \mathrm{cm}$ shows $\varepsilon_{33}^{T} / \varepsilon_{0}$ and $d_{33}$ of 7270 and 2370 $\mathrm{pC} / \mathrm{N}$, which increased by $4 \%$ and $1 \%$, respectively, slightly more than those of high temperature (HT) ACP (No. 2) with the same poling voltage. It reveals that FC ACP would enhance piezoelectric properties by applying AC field through dynamic multi-phase transition during cooling procedure. However, when FC poling temperature ranges from 100 to $80{ }^{\circ} \mathrm{C}$ with $0.2 \mathrm{~Hz}$ (No. 4), all properties decreased to the level $\left(\varepsilon_{33}^{T} / \varepsilon_{0}=\right.$ $6720, d_{33}=2310 \mathrm{pC} / \mathrm{N}$ ) below that of No. 2. Therefore, we optimally adjusted the conditions, including increasing poling voltage to $6 \mathrm{kV}_{\mathrm{rms}} / \mathrm{cm}$, decreasing frequency to $0.1 \mathrm{~Hz}$, and setting end temperature point at $70{ }^{\circ} \mathrm{C}$. Dielectric properties, which continue to rise while temperature end point decreased to $60{ }^{\circ} \mathrm{C}$ (No. 6), increased significantly by $18 \%$ comparing with those of the former (No. 4). It indicates that high voltage $\mathrm{ACP}$ at low poling temperature is an effective method to enhance properties. Given that moderately increasing poling temperature could decrease the $E_{\mathrm{c}}$, and thus effectively reduce the poling voltage [29], we reduced the poling voltage to $4 \mathrm{kV}_{\text {rms }} / \mathrm{cm}$ and changed the cooling region from 100 to $70{ }^{\circ} \mathrm{C}$. Thus, the best properties $\left(\varepsilon_{33}^{T} / \varepsilon_{0}=8330, k_{33}=0.96\right)$ including the ultrahigh piezoelectricity $\left(d_{33}=2750 \mathrm{pC} / \mathrm{N}\right)$ were attained as shown in Fig. 2(a). The $\varepsilon_{33}^{T} / \varepsilon_{0}$ and $d_{33}$ were enhanced by $19 \%$ and $18 \%$, respectively, compared to those of HT ACP (No. 2), and $k_{33}=0.96$ is the highest ever reported as PIMN $-x$ PT SCs as authors know. The lowest $\varepsilon_{33}^{T} / \varepsilon_{0}=5110$ and $d_{33}=1760 \mathrm{pC} / \mathrm{N}$ for the same SC after HT DCP (No. 1) may be due to over poling by high voltage [26,34]. And comparison of $\varepsilon_{33}^{T} / \varepsilon_{0}$ and $d_{33}$ with different poling conditions of PIMN $-x$ PT SCs is illustrated in Fig. 2(b). Compared with HT DCP, PIMNT SC after the HT ACP obtains (a)

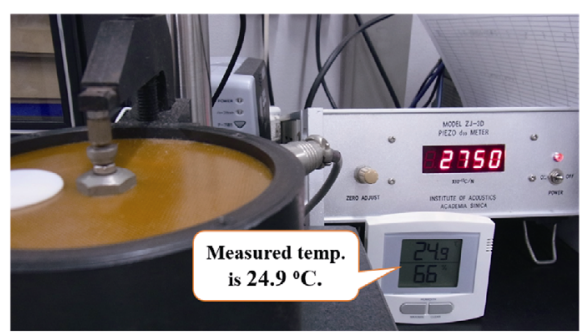

(b)

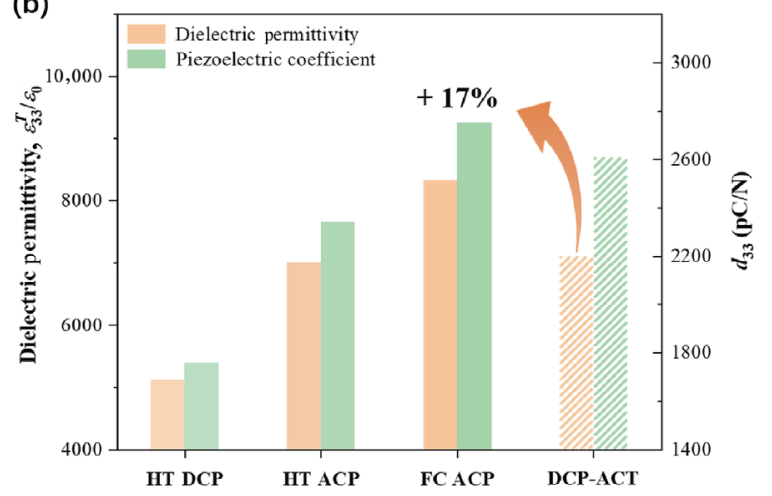

Fig. 2 (a) Real measured value of the ultrahigh $d_{33}$ and (b) comparison of $\varepsilon_{33}^{T} / \varepsilon_{0}$ and $d_{33}$ among HT DCP, HT ACP [29], FC ACP, and DCP-ACT [19] of PIMN-xPT SCs.

about $33 \%$ increment of $d_{33}$ which continues to grow by $18 \%$ after the FC ACP. Meanwhile, $\varepsilon_{33}^{T} / \varepsilon_{0}$ of the FC ACP was $17 \%$ higher than that of DCP-ACT (ACT: alternating current treatment) [19] possessing higher $T_{\mathrm{pc}}=114{ }^{\circ} \mathrm{C}$. Therefore, PIMN-0.30PT SC can achieve significant performance improvement through multiphase transition by ACP during FC process.

Temperature dependence of $\varepsilon_{33}^{T} / \varepsilon_{0}$ and $\tan \delta$ of the sample No. 7 in Table 1 is performed as shown in Fig. 3. FC ACP SC has two distinct dielectric peaks at around 103 and $116{ }^{\circ} \mathrm{C}$ of $\varepsilon_{33}^{T} / \varepsilon_{0}$, the same as those of $\tan \delta$ before phase changing from $\mathrm{T}$ to $\mathrm{C}$, which can be attributed to phase transitions of $\mathrm{R}$ to $\mathrm{M}\left(T_{\mathrm{RM}}\right)$ and $\mathrm{M}$ to $\mathrm{T}\left(T_{\mathrm{MT}}\right)$, respectively $[10,25]$. Furthermore, two 
(a)

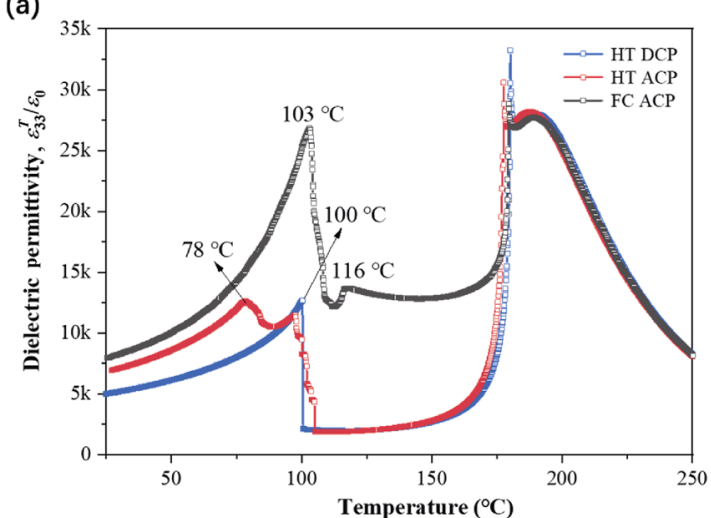

(b)

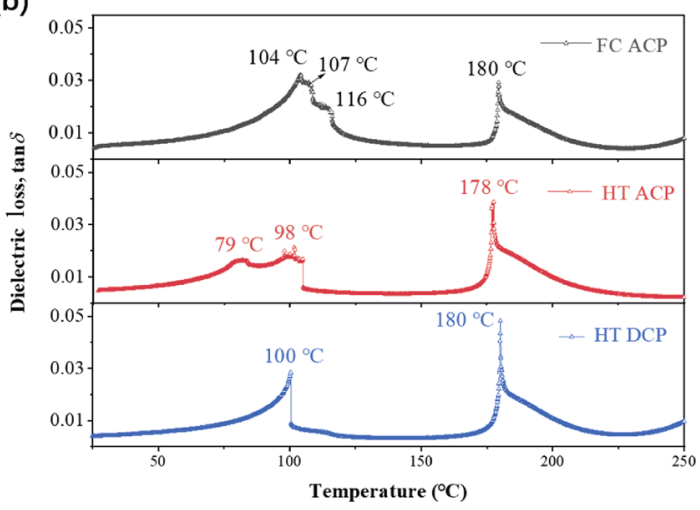

Fig. 3 Temperature dependence of (a) $\varepsilon_{33}^{T} / \varepsilon_{0}$ and (b) $\tan \delta$ of PIMN-0.30PT SCs poled by HT DCP, HT ACP [29], and the optimized FC ACP.

peaks of HT ACP and one peak of HT DCP before $T_{\mathrm{C}}$ point also proved the existence of $\mathrm{M}$ phase after ACP [26,29]. Compared with the HT ACP crystal, as shown in Fig. 3(b), three dielectric loss peaks appear at 104, 107 , and $116{ }^{\circ} \mathrm{C}$, which further reflects the induced phase path of $\mathrm{R} \rightarrow \mathrm{MA} \rightarrow \mathrm{MC} \rightarrow \mathrm{T}[19,38]$ by FC ACP. Thus, we speculated that there are two kinds of distinct phase change order between $\mathrm{R}$ and $\mathrm{T}$ phase transition $[39,40]$. Moreover, it is worth noting that FC ACP SC not only improves performance, but also has a significant increment of $T_{\mathrm{pc}}$ comparing with that of HT ACP $\left(T_{\mathrm{RM}}=78{ }^{\circ} \mathrm{C}\right)[19,31]$. Therefore, the greater electric and thermal performance improvement of PIMN-0.30PT SC is attributed to the low symmetry multi-phase constructed by phase changing through dynamic ACP cooling procedure.

These $\varepsilon_{33}^{T} / \varepsilon_{0}$ and $d_{33}$ of various PMN-based relaxor SCs and their corresponding $T_{\mathrm{pc}}$ and $T_{\mathrm{C}}$ are shown in Figs. 4(a) and 4(b), respectively. We found that the electric properties are often in inverse proportion to the thermal properties among diversified SCs. It means that relaxor SCs with higher electrical properties usually cannot have higher thermal stability $\left(T_{\mathrm{pc}}\right.$ above
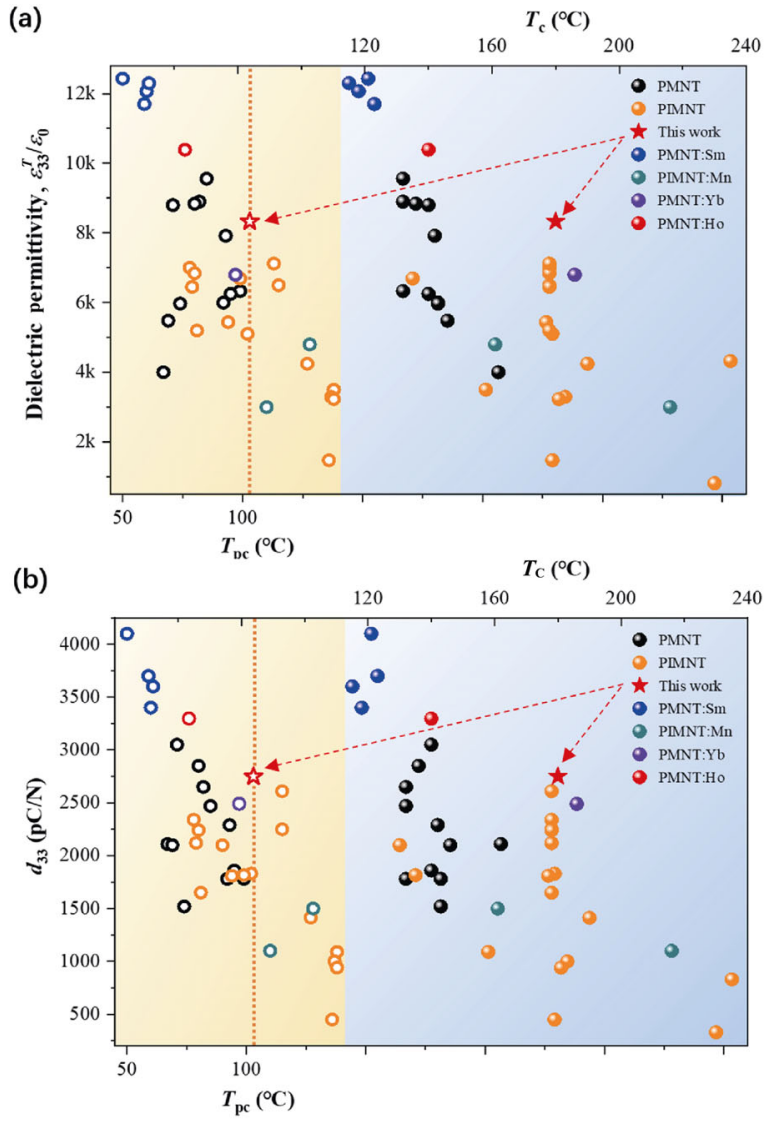

Fig. 4 (a) $\varepsilon_{33}^{T} / \varepsilon_{0}$ and (b) $d_{33}$ of various PMN-based relaxor SCs, and their corresponding $T_{\mathrm{pc}}$ and $T_{\mathrm{C}}[4,11,12$, $14,15,17,19-21,25,26,29,39,41,42]$.

$\left.100{ }^{\circ} \mathrm{C}\right)$. However, in this work, after FC ACP PIMN-0.30PT possesses higher $T_{\mathrm{pc}}$ of $103{ }^{\circ} \mathrm{C}$ and $T_{\mathrm{C}}$ of $180{ }^{\circ} \mathrm{C}$ while obtaining the highest $\varepsilon_{33}^{T} / \varepsilon_{0}$ and $d_{33}$ among all binary and ternary PMN-based relaxor SC systems. Thus, the ultrahigh electric performance and thermal stability, these two major advantages, are both achieved in the PIMNT SC after FC ACP successfully.

To clarify the polarization mechanism clearly, we analyzed the difference between dynamic ACP and static DCP through contrast domain size and polar direction of multiple joints during electric poling, as shown in Fig. 5. We can see that initial polar direction is randomly distributed inside the unpoled SCs, as shown in Figs. 5(a) and 5(b). As poling electric voltage increasing, most of polar directions begin to arrange along one direction, as shown in Figs. 5(c) and 5(d). Since voltage direction of AC electric field dynamically reverses, the polar direction and domain structure would also be changed, as shown in Fig. 5(e). However, after certain duration, the domain structure does not change significantly inside SC because of the single 


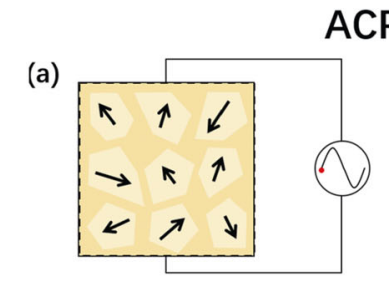

(c)

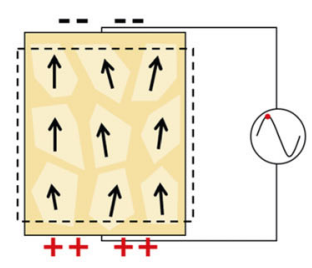

(e)

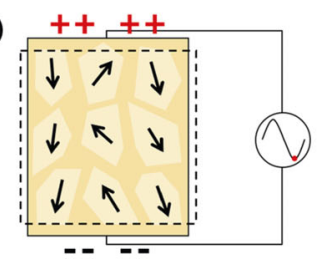

(i)

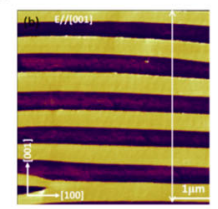

$\varepsilon_{33}^{T} / \varepsilon_{0}=6800$

$d_{33}=2490 \mathrm{pC} / \mathrm{N}$

(g)

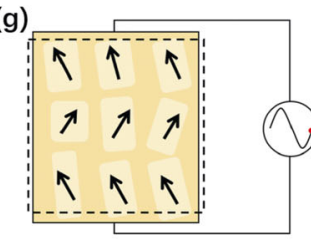

(j)

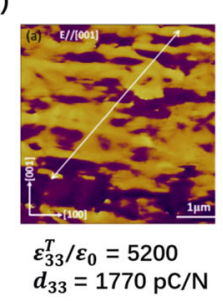

DCP

(b)

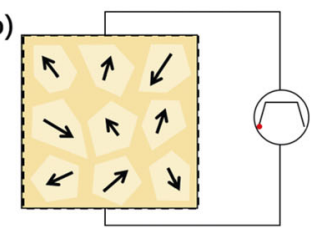

(d)

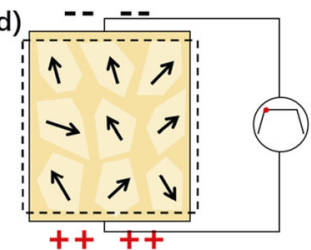

(h)

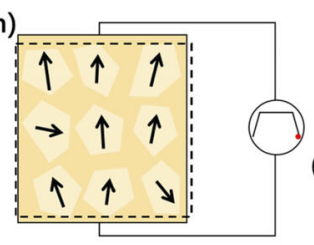

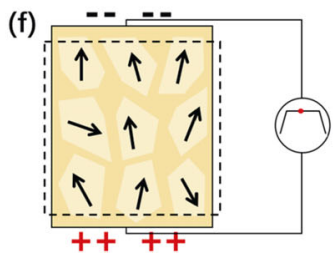

Fig. 5 Schematic images of (a), (c), (e), and (g) dynamic ACP and (b), (d), (f), and (h) static DCP processes; lateral phase of domain patterns observed on the fresh fracture of the ternary PMN-based SC after (i) ACP and (j) DCP. The PFM images are referred from He et al. [14].

direction and stable value of DC electric voltage, as shown in Fig. 5(f). On the contrary, the domain structure and polar direction of SC after ACP gradually tend to be orderly as poling direction reversal repeated several times, as shown in Fig. 5(g). And with applying periodic voltage, inner structures would also be changed by the external factors, such as frequencies and number of cycles $[7,8,14,30,31]$. In the end, a uniform stripe-like layer $109^{\circ}$ domain structure ranging from 1 to $2 \mu \mathrm{m}$, similar to the piezoelectric force microscopy (PFM) pattern shown in Fig. 5(i), forms in ACP SC instead of the dispersed domain structure after DCP in Fig. 5(j) [7,14]. Moreover, outstanding properties, such as the ultrahigh piezoelectricity and transparency, are proved to be attributed to the extrinsic contribution of larger domain size, $109^{\circ}$ domain wall, and periodic domain configuration $[17,30]$. Besides, dynamic polarization is easier to utilize reverse potential to eliminate the pinning effect generated in spontaneous polarization compared to static poling [28]. Thus, we consider that the ordering domain configurations with proper domain size also contribute to excellent electric and thermal performance of PIMNT SCs [31].

Based on the current compositions and $T_{\mathrm{pc}}$ after JFE Mineral Co. standard poling condition [4], we proposed a composition-temperature phase diagram of PIMN- $x$ PT system manufactured by CF BM process.
As shown in Fig. 6(a), we update schematic phase diagram after ACP according to previous work [25,29]. The various monoclinic phases diffuse into the $\mathrm{R}$ and $\mathrm{T}$ regions, as shown in Figs. 6(a) and 6(b). Thus, MPB is not a narrow compositional region containing low symmetry phases any more, but an extremely broad region with co-existing phases significantly expands into the adjacent phase regions. As PT content increasing, the $T_{\mathrm{C}}$ increases linearly, whereas the $T_{\mathrm{pc}}$ after ACP slightly increases at first, and then $T_{\mathrm{RM}}$ and $T_{\mathrm{MT}}$ decrease to RT at higher PT composition (Fig. 6(b)). With further increment of PT, low symmetry phases act as a bridge between $\mathrm{R}$ and $\mathrm{T}$ in such a broad composition region with co-existing phases. It indicates a relationship among various ferroelectric phases with different polarization vectors. And polarization vectors rotate to the $[001]_{\mathrm{pc}}$ direction in each domain under $[001]_{\mathrm{pc}}$ electric field resulting in large piezoelectric distortion. These differences in the orientation within plane where the polarization lies, are often designated $\mathrm{M}_{\mathrm{A}}, \mathrm{M}_{\mathrm{B}}, \mathrm{M}_{\mathrm{C}}$, and orthorhombic $(\mathrm{O})$, as shown in Fig. 6(c). This model is informed by $\mathrm{X}$-ray diffraction under applied field, confirming that the phase transition under increasing applied fields transforms from approximately $\mathrm{R}$, through low symmetry phases to the $\mathrm{T}$ [43]. In the $\mathrm{M}_{\mathrm{B}}$ and $\mathrm{O}$ phases, the polarization vector lies within a $(100)_{\mathrm{pc}}$ plane, while the polarization vectors of the $\mathrm{M}_{\mathrm{A}}$ and $\mathrm{M}_{\mathrm{C}}$ phases lie within $(110)_{\mathrm{pc}}$ 
(a)

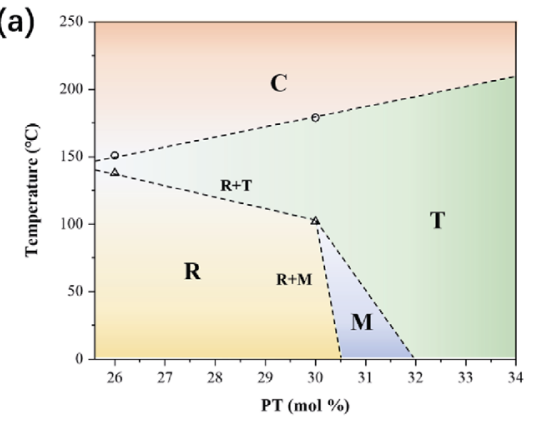

(d)

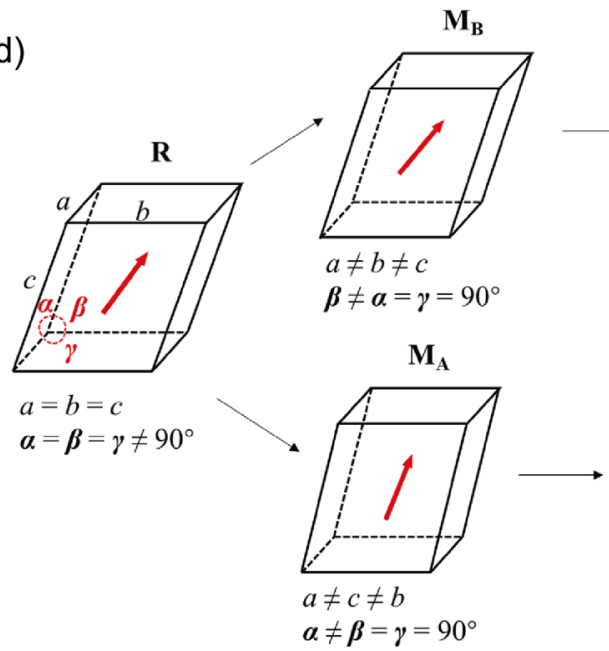

(b)

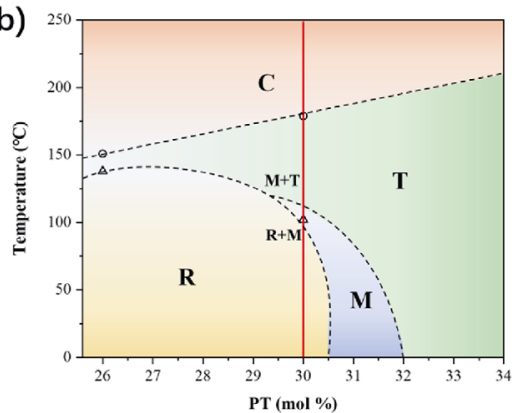

o

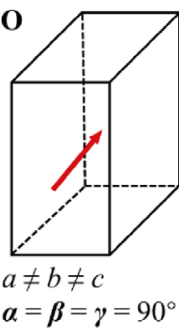

$\mathbf{M}_{\mathrm{C}}$

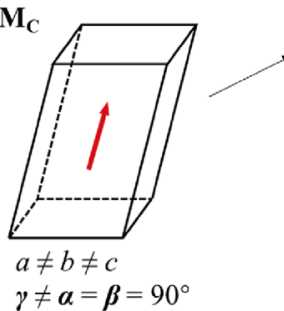

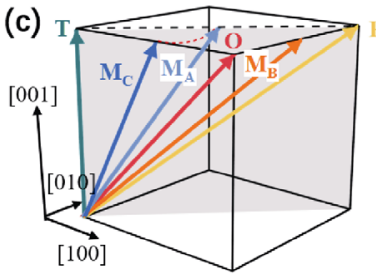

(c)

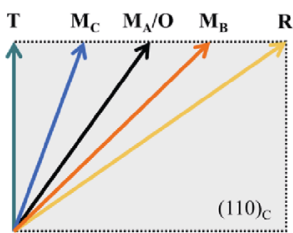

Fig. 6 Schematic phase diagram of CF BM PINMT system of (a) DCP and (b) ACP; (c) possible polarization vectors of low symmetry phases $\left(\mathrm{M}_{\mathrm{A}}, \mathrm{M}_{\mathrm{B}}, \mathrm{M}_{\mathrm{C}}\right.$, and $\left.\mathrm{O}\right), \mathrm{R}$ and $\mathrm{T}$ phases in perovskite crystals, and polarization projection on the (110) plane; and (d) illustration of lattice deformations for the two paths of phase transition from RT to HT over $T_{\mathrm{C}}$.

plane and $(010)_{\mathrm{pc}}$ plane, respectively. To reveal the phase rotation behaviors clearly, we proposed the polarization projection on the (110) $)_{\mathrm{pc}}$ face. As illustrated in Fig. 6(c, bottom), the extinction angle is equivalent to the angle between the projection of spontaneous polarization on the $(110)_{\mathrm{pc}}$ face and the $[001]_{\mathrm{pc}}$ axis. Accordingly, polarization rotation path can be tracked in the $(110)_{\mathrm{pc}}$ plane through domain observation by using polarizing microscope (PLM) with a crossed polarizer/analyzer (P/A) pair [39]. As reported by Bell et al. [40] and Fu et al. [43], on applying an increasing electric field to a $[001]_{\text {pc }}$-poled SC, there are two polarization rotating paths from $\mathrm{R}$ and $\mathrm{T}$ phases via low symmetry. As shown in Fig. 6(d), top path is $M_{B}$ switching to $O$ within the $(100)_{\mathrm{pc}}$ plane, and bottom path is $\mathrm{M}_{\mathrm{A}}$ to $\mathrm{M}_{\mathrm{C}}$ with the polarization rotation within $(110)_{\mathrm{pc}}$ towards $(010)_{\mathrm{pc}}$ plane. A small electric field will induce a large strain level (thus a large piezoelectricity) in low-field region, switching via the $\mathrm{M}_{\mathrm{A}}$ and $\mathrm{M}_{\mathrm{C}}$ phases is more feasible compared to the other continuous path due to the minimum energy during polarization rotation [43]. Thus, more characterization methods are necessary to clarify the specific phase transition process and phase parameters in future research.

\section{Conclusions}

In this paper, we studied dielectric, piezoelectric, and electromechanical properties of [001 $]_{\mathrm{pc}}$-oriented PIMN0.30PT SCs manufactured by CF BM method in the MPB region nearby $\mathrm{R}$ structure after FC ACP. We found the optimal polarization conditions, $4 \mathrm{kVrms} / \mathrm{cm}$, $0.1 \mathrm{~Hz}$, and 20 cycles from 100 to $70{ }^{\circ} \mathrm{C}$, and attained excellent properties, $\varepsilon_{33}^{T} / \varepsilon_{0}$ of $8330, d_{33}$ of $2750 \mathrm{pC} / \mathrm{N}$, and $k_{33}$ of 0.96 with higher $T_{\mathrm{pc}}$ of $103{ }^{\circ} \mathrm{C}$. These values are the highest among all binary and ternary relaxor-PT SCs with $T_{\mathrm{pc}}>100{ }^{\circ} \mathrm{C}$. Optimizing FC conditions based on previous experiment, the ACP process improved the electrical performance through inducing the crucial low symmetry phases inside SCs by multi-phase transition during cooling process. While significantly improving the electric performance of the SCs, the FC ACP also increases the $T_{\mathrm{pc}}$ compared to HT ACP SCs. It makes wider temperature application 
of the SC compared to binary SC PMN-PT. This work shows that FC ACP is a convenient and effective method to enhance piezoelectricity of relaxor-PT SCs including PIMN $-x \mathrm{PT}$, and promotes the development of a wide range of piezoelectric device applications.

\section{Acknowledgements}

This research work was partly supported by the Murata Science Foundation Japan (H31JOJI022).

\section{References}

[1] Zhang S, Li F, Jiang X, et al. Advantages and challenges of relaxor- $\mathrm{PbTiO}_{3}$ ferroelectric crystals for electroacoustic transducers-A review. Prog Mater Sci 2015, 68: 1-66.

[2] Zhang S, Li F, Yu F, et al. Recent developments in piezoelectric crystals. J Korean Ceram Soc 2018, 55: 419-439.

[3] Jiang X, Al-Jumaily AM. Ultrasound transducers for biomedical imaging and therapy. J Eng Sci Med Diagn Ther 2018, 1: 040201.

[4] Matsushitata M, Echizenya K. Continuous feeding growth of ternary PIN-PMN-PT single crystals. In: Proceedings 2014 Joint IEEE International Symposium on the Applications of Ferroelectric, International Workshop on Acoustic Transduction Materials and Devices \& Workshop on Piezoresponse Force Microscopy, 2014: 1-4.

[5] Information on https://jfe-mineral.co.jp/e_mineral/business/ advanced_material/piezoelectric_single_crystal.html, 2021.

[6] Zhang S, Li F, Sherlock NP, et al. Recent developments on high Curie temperature PIN-PMN-PT ferroelectric crystals. J Cryst Growth 2011, 318: 846-850.

[7] Yamamoto N, Yamashita Y, Hosono Y, et al. Ultrasonic probe, piezoelectric transducer, method of manufacturing ultrasonic probe, and method of manufacturing piezoelectric transducer. U.S. Patent 9966 524, May 2018.

[8] Yamashita Y, Yamamoto N, Hosono Y, et al. Piezoelectric transducer, ultrasonic probe, and piezoelectric transducer manufacturing method. U.S. Patent 9972 766, May 2018.

[9] Xu J, Deng H, Zeng Z, et al. Piezoelectric performance enhancement of $\mathrm{Pb}\left(\mathrm{Mg}_{1 / 3} \mathrm{Nb}_{2 /}\right) \mathrm{O}_{3}-0.25 \mathrm{PbTiO}_{3}$ crystals by alternating current polarization for ultrasonic transducer. Appl Phys Lett 2018, 112: 182901.

[10] Chang W, Chung C, Luo C, et al. Dielectric and piezoelectric properties of $0.7 \mathrm{~Pb}\left(\mathrm{Mg}_{1 / 3} \mathrm{Nb}_{23}\right) \mathrm{O}_{3}-0.3 \mathrm{PbTiO}_{3}$ single crystal poled using alternating current. Mater Res Lett 2018, 6: 537-544.

[11] Qiu CR, Liu JF, Li F, et al. Thickness dependence of dielectric and piezoelectric properties for alternating current electric-field-poled relaxor- $\mathrm{PbTiO}_{3}$ crystals. $\mathrm{J} \mathrm{Appl}$ Phys 2019, 125: 014102.

[12] Zhang $\mathrm{Z}, \mathrm{Xu} \mathrm{JL}$, Yang LL, et al. The performance enhancement and temperature dependence of piezoelectric properties for $\mathrm{Pb}\left(\mathrm{Mg}_{1 / 3} \mathrm{Nb}_{2 \beta}\right) \mathrm{O}_{3}-0.30 \mathrm{PbTiO}_{3}$ single crystal by alternating current polarization. J Appl Phys 2019, 125: 034104.

[13] Wan HT, Luo C, Chang WY, et al. Effect of poling temperature on piezoelectric and dielectric properties of $0.7 \mathrm{~Pb}\left(\mathrm{Mg}_{1 / 3} \mathrm{Nb}_{23}\right) \mathrm{O}_{3}-0.3 \mathrm{PbTiO}_{3}$ single crystals under alternating current poling. Appl Phys Lett 2019, 114: 172901.

[14] He C, Karaki T, Yang XM, et al. Dielectric and piezoelectric properties of $\mathrm{Pb}\left[\left(\mathrm{Mg}_{1 / 3} \mathrm{Nb}_{2 / 3}\right)_{0.52}\left(\mathrm{Yb}_{1 / 2} \mathrm{Nb}_{1 / 2}\right)_{0.15} \mathrm{Ti}_{0.33}\right] \mathrm{O}_{3}$ single-crystal rectangular plate and beam mode transducers poled by alternate current poling. Jpn J Appl Phys 2019, 58: SLLD06.

[15] Sun YQ, Karaki T, Fujii T, et al. Alternate current poling and direct current poling for $\mathrm{Pb}\left(\mathrm{Mg}_{1 / 3} \mathrm{Nb}_{2 / 3}\right) \mathrm{O}_{3}-\mathrm{PbTiO}_{3}$ single crystals. Jpn J Appl Phys 2019, 58: SLLC06.

[16] Luo C, Wan HT, Chang WY, et al. Effect of low-frequency alternating current poling on 5-mm-thick $0.7 \mathrm{~Pb}\left(\mathrm{Mg}_{1 / 3} \mathrm{Nb}_{23}\right) \mathrm{O}_{3}-0.3 \mathrm{PbTiO}_{3}$ single crystals. Appl Phys Lett 2019, 115: 192904.

[17] Qiu C, Wang B, Zhang N, et al. Transparent ferroelectric crystals with ultrahigh piezoelectricity. Nature 2020, 577 : 350-354.

[18] Lee GJ, Kim HP, Lee SG, et al. Depolarization mechanism of alternating-current-poled $\mathrm{Pb}\left(\mathrm{Mg}_{1 / 3} \mathrm{Nb}_{2 / 3}\right) \mathrm{O}_{3}-\mathrm{PbTiO}_{3}$ single crystals measured using in-situ thermally stimulated depolarization current. J Sensor Sci Technol 2020, 29: 59-62.

[19] Ma M, Xia S, Song KX, et al. Enhanced dielectric and piezoelectric properties in the [001]-poled $0.25 \mathrm{~Pb}\left(\operatorname{In}_{12} \mathrm{Nb}_{12}\right) \mathrm{O}_{3}$ $0.43 \mathrm{~Pb}\left(\mathrm{Mg}_{1 / 3} \mathrm{Nb}_{2 /}\right) \mathrm{O}_{3}-0.32 \mathrm{PbTiO}_{3}$ single crystal near morphotropic phase boundary by alternating current treatment. J Appl Phys 2020, 127: 064106.

[20] Jiang Z, Ye Z. Application study of Mn-doped PINPMN-PT relaxor ferroelectric crystal grown by vertical gradient freeze method. Ferroelectrics 2020, 557: 9-17.

[21] Guo L, Su B, Wang CX, et al. Orientation dependence of dielectric and piezoelectric properties of tetragonal relaxor ferroelectric single crystals by alternate current poling. $J$ Appl Phys 2020, 127: 184104.

[22] Xu JL, Zhang Z, Liu SX, et al. Optimizing the piezoelectric vibration of $\mathrm{Pb}\left(\mathrm{Mg}_{1 / 3} \mathrm{Nb}_{2 / 3}\right) \mathrm{O}_{3}-0.25 \mathrm{PbTiO}_{3}$ single crystal by alternating current polarization for ultrasonic transducer. Appl Phys Lett 2020, 116: 202903.

[23] Zhang Z, Xu JL, Liu SX, et al. FEM simulation and comparison of PMN-PT single crystals based phased array ultrasonic transducer by alternating current poling and direct current poling. Ultrasonics 2020, 108: 106175.

[24] Liu JF, Qiu CR, Qiao L, et al. Impact of alternating current electric field poling on piezoelectric and dielectric properties of $\mathrm{Pb}\left(\mathrm{In}_{1 / 2} \mathrm{Nb}_{1 / 2}\right) \mathrm{O}_{3}-\mathrm{Pb}\left(\mathrm{Mg}_{1 / 3} \mathrm{Nb}_{2 / 3}\right) \mathrm{O}_{3}-\mathrm{PbTiO}_{3}$ ferroelectric crystals. J Appl Phys 2020, 128: 094104.

[25] Luo C, Karaki T, Sun YQ, et al. Effect of field cooling AC poling on electrical and physical properties for 
$\mathrm{Pb}\left(\mathrm{Mg}_{1 / 3} \mathrm{Nb}_{2 / 3}\right) \mathrm{O}_{3}-\mathrm{PbTiO}_{3}$-based single crystals manufactured by a continuous-feeding Bridgman process. Jpn J Appl Phys 2020, 59: SPPD07.

[26] Sun YQ, Karaki T, Fujii T, et al. Enhanced electric property of relaxor ferroelectric crystals with low AC voltage high-temperature poling. Jpn J Appl Phys 2020, 59: SPPD08.

[27] Wan HT, Kim H, Wu HY, et al. Characterization of high-frequency ultrasound transducers made of alternating current poled $\mathrm{Pb}\left(\mathrm{Mg}_{1 / 3} \mathrm{Nb}_{2 / 3}\right) \mathrm{O}_{3}-x \mathrm{PbTiO}_{3}$ single crystals. In: Proceedings of the IEEE International Ultrasonics Symposium, 2020: 1-4.

[28] Yamashita Y, Sun YQ, Luo C et al. Lead perovskite piezoelectric single crystals and AC poling method. $J$ Technol 2020, 20: 299-314. (in Chinese)

[29] Luo C, Karaki T, Yamashita Y, et al. High temperature and low voltage $\mathrm{AC}$ poling for $0.24 \mathrm{~Pb}\left(\mathrm{In}_{1 / 2} \mathrm{Nb}_{1 / 2}\right) \mathrm{O}_{3}-$ $0.46 \mathrm{~Pb}\left(\mathrm{Mg}_{1 / 3} \mathrm{Nb}_{2 / 3}\right) \mathrm{O}_{3}-0.30 \mathrm{PbTiO}_{3}$ piezoelectric single crystals manufactured by continuous-feeding Bridgman method. J Materiomics 2021, 7: 621-628.

[30] Wan HT, Luo C, Liu C, et al. Alternating current poling on sliver-mode rhombohedral $\mathrm{Pb}\left(\mathrm{Mg}_{1 / 3} \mathrm{Nb}_{2 /}\right) \mathrm{O}_{3}-\mathrm{PbTiO}_{3}$ single crystals. Acta Mater 2021, 208: 116759.

[31] Wan HT, Luo C, Chung CC, et al. Enhanced dielectric and piezoelectric properties of manganese-doped $\mathrm{Pb}\left(\mathrm{In}_{12} \mathrm{Nb}_{12}\right) \mathrm{O}_{3}-$ $\mathrm{Pb}\left(\mathrm{Mg}_{1 / 3} \mathrm{Nb}_{2 / 3}\right) \mathrm{O}_{3}-\mathrm{PbTiO}_{3}$ single crystals by alternating current poling. J Appl Phys Lett 2021, 118: 102904.

[32] Xiong JJ, Wang ZJ, Yang XM, et al. Effects of alternating current poling on the dielectric and piezoelectric properties of $\mathrm{Pb}\left(\mathrm{In}_{0.5} \mathrm{Nb}_{0.5}\right) \mathrm{O}_{3}-\mathrm{PbTiO}_{3}$ crystals with a high Curie temperature. RSC Adv 2021, 11: 12826-12832.

[33] Xiong JJ, Wang ZJ, Yang XM, et al. Optimizing the piezoelectric and dielectric properties of $\mathrm{Pb}\left(\mathrm{In}_{1 / 2} \mathrm{Nb}_{1 / 2}\right) \mathrm{O}_{3}-$ $\mathrm{PbTiO}_{3}$ ferroelectric crystals via alternating current poling waveform. IEEE Trans Ultrason Ferroelectr Freq Control 2021, 68: 2775-2780.

[34] Sun YQ, Karaki T, Fujii T, et al. Spurious-mode vibrations caused by alternating current poling and their solution process for $\mathrm{Pb}\left(\mathrm{Mg}_{1 / 3} \mathrm{Nb}_{2 \beta}\right) \mathrm{O}_{3}-\mathrm{PbTiO}_{3}$ single crystals. $J$ Materiomics 2021, https://doi.org/10.1016/j.jmat.2021.05.002.

[35] Electronic Industries Alliance. EIA 198-1 Standard. Ceramic dielectric capacitors classes I, II, III and IV-Part I: Characteristics and requirements. 2002. Available at https://global.ihs.com/doc_detail.cfm?item_s_key $=00033060$.
[36] IEEE. IEEE Std 1859-2017. IEEE standard for relaxorbased single crystals for transducer and actuator applications. 2017. Available at https://standards.ieee.org/ standard/1859-2017.html.

[37] Qiao L, Li Q, Qiu CR, et al. Temperature dependence of elastic, piezoelectric, and dielectric matrixes of [001]-poled rhombohedral PIN-PMN-PT single crystals. IEEE Trans Ultrason Ferroelectr Freq Control 2019, 66: 1786-1792.

[38] Chen JW, Li XB, Zhao XY, et al. Compositional segregation, structural transformation and propertytemperature relationship of high-Curie temperature $\mathrm{Pb}\left(\mathrm{In}_{1 / 2} \mathrm{Nb}_{1 / 2}\right) \mathrm{O}_{3}-\mathrm{Pb}\left(\mathrm{Mg}_{1 / 3} \mathrm{Nb}_{2 /}\right) \mathrm{O}_{3}-\mathrm{PbTiO}_{3}$ single crystals. J Mater Sci: Mater Electron 2015, 26: 9316-9328.

[39] Fan J, Lu X, Cao W. Phase transitions and piezoelectricity enhancement around $\mathrm{M}_{\mathrm{C}} \rightarrow \mathrm{O}$ phase transition in PMN-0.34PT single crystals. $J$ Alloys Compd 2020, 835: 155171.

[40] Bell AJ, Shepley PM, Li Y. Domain wall contributions to piezoelectricity in relaxor-lead titanate single crystals. Acta Mater 2020, 195: 292-303.

[41] Li XZ, Wang ZJ, He C, et al. High piezoelectric response of a new ternary ferroelectric $\mathrm{Pb}\left(\mathrm{Ho}_{12} \mathrm{Nb}_{12}\right) \mathrm{O}_{3}-\mathrm{Pb}\left(\mathrm{Mg}_{13} \mathrm{Nb}_{23}\right) \mathrm{O}_{3}-$ $\mathrm{PbTiO}_{3}$ single crystal. Mater Lett 2015, 143: 88-90.

[42] Li F, Cabral MJ, Xu B, et al. Giant piezoelectricity of Sm-doped $\mathrm{Pb}\left(\mathrm{Mg}_{1 / 3} \mathrm{Nb}_{2 / 3}\right) \mathrm{O}_{3}-\mathrm{PbTiO}_{3}$ single crystals. Science 2019, 364: 264-268.

[43] Fu H, Cohen RE. Polarization rotation mechanism for ultrahigh electromechanical response in single-crystal piezoelectrics. Nature 2000, 403: 281-283.

Open Access This article is licensed under a Creative Commons Attribution 4.0 International License, which permits use, sharing, adaptation, distribution and reproduction in any medium or format, as long as you give appropriate credit to the original author(s) and the source, provide a link to the Creative Commons licence, and indicate if changes were made.

The images or other third party material in this article are included in the article's Creative Commons licence, unless indicated otherwise in a credit line to the material. If material is not included in the article's Creative Commons licence and your intended use is not permitted by statutory regulation or exceeds the permitted use, you will need to obtain permission directly from the copyright holder.

To view a copy of this licence, visit http://creativecommons. org/licenses/by/4.0/. 